\title{
Un ensayo para la reestructuración del Mercado de Talca
}

\author{
An essay for the restructuring of the Talca Market
}

\author{
JAVIERA STAIG MUÑOZ \\ Escuela de Arquitectura \\ Universidad de Talca. Talca, Chile \\ jstaigmunoz@gmail.com
}

\section{RESUMEN}

La identidad es un término asociado a un continuo, que está vinculado con lo más interno de las personas y con los rasgos que identifican a las naciones, a partir de una similitud entre los individuos que la componen. Por ello, el siguiente ensayo tiene como propósito analizar, de manera crítica, el proceso de abandono del Mercado Central de Talca (tras el terremoto del 27 de febrero de 2010) y su reconstrucción. En tal sentido, se plantea un análisis de la raíz histórica de los intereses comerciales de grandes empresas y como esto influyó en el daño al patrimonio histórico y en el origen de la identidad e idiosincrasia de las comunidades de los talquinos que se relacionan con el Mercado. Asimismo, se revisan diversas propuestas para la preservación del Mercado. Se concluye que es necesario conservar el patrimonio arquitectónico-histórico y priorizar las necesidades de las comunidades.

Palabras clave: Reconstrucción, patrimonio arquitectónico, Mercado Central de Talca, identidad. 


\section{ABSTRACT}

Identity is a term associated with a continuum, which is linked to the innermost of people and to the features that identify nations, based on a similarity between the individuals that compose it. Therefore, the following essay aims to analyze, critically, the process of abandonment of the Central Market of Talca (after the earthquake of February 27,2010 ) and its reconstruction. In this regard, an analysis of the historical roots of the commercial interests of large companies is proposed and how this influenced the damage to the historical heritage and the origin of the identity and idiosyncrasies of the Talquino communities that are related to the Market. Likewise, various proposals for the preservation of the Market are reviewed. It is concluded that it is necessary to preserve the architectural-historical heritage and prioritize the needs of the communities.

Key words: Reconstruction, architectural heritage, Central Market of Talca, identity.

\section{Introducción}

Cada lugar en el mundo posee características determinadas en cuanto a la cultura y la expresión de su forma de habitar. Esto se ha desarrollado de diferentes maneras a través del tiempo, según la evolución de cada sociedad, sentando las bases de lo que hoy llamamos identidad.

La identidad se reconoce como un concepto amplio, que abarca desde el aspecto más íntimo del ser humano (las características que nos hacen únicos) hasta los rasgos más representativos de las grandes naciones.

Del latín identitas, "lo mismo" (Real Academia Española, 2019), la identidad se vale de diversos modos y costumbres para generar una clasificación de masas. En ese sentido, se puede hacer referencia a la identidad occidental, caracterizada por un feroz desapego a los ancestros y al planeta, al considerarlos obsoletos y arrasando con todo, en pos del confort y del desarrollo.

Por otro lado, la identidad de las comunidades se transforma en patrimonio, un término que revela la herencia de lo propio y de lo histórico por sobre lo moderno y extranjero. Incluso, configura un sentido para definir lo autóctono y el empoderamiento territorial que se representa en el patrimonio arquitectónico histórico (Dormaels, 2012). 
Al respecto, en el caso del Mercado Central de Talca, la participación de los locatarios es la que sustenta el patrimonio que identifica a la región, en defensa del espacio democrático del comercio de barrio. Además, protege el recinto del modelo económico consumista e individualista, de inmobiliarias o de convertirse en un centro comercial o cívico, perdiendo con ello la visión de lo propio.

Ese proceso de defensa del patrimonio, a través del activismo local, es similar a las experiencias observadas en las zonas típicas de Viel y Yungay en Santiago (Uribe, 2014).

Por ello, en este escrito indaga sobre la identidad de la zona centro de Chile, su urbanismo y arquitectura, específicamente en Talca, con la intención de determinar los diversos factores que involucran el actual abandono del Mercado Central, además de analizar algunos aspectos que favorezcan una posible reconstrucción o recuperación del patrimonio arquitectónico que representa al territorio y legitima el sentido de vida de los talquinos.

\section{Desarrollo}

Europa, como pionero en el desarrollo social, influenció a la mayoría de los países de Occidente (Vuletich \& Navarrete, 2010). En ese sentido, Chile fue un lugar habitado por aborígenes, que poseían una organización social carente de estamentos.

Esa población era, principalmente, nómada, y se caracterizaba por el cuidado y respeto a la naturaleza, la cual se asociaba a lo divino, a la existencia y a los bienes necesarios para el diario vivir. Sin embargo, con la llegada de los españoles, la población fue intervenida violentamente (Memoria Chilena, 2019). Como resultado de lo anterior, se produjo una migración campo-ciudad, que provocó una centralización urbanística del capital político, económico y social. Además, con el desarrollo y la globalización, las casas coloniales -junto a las edificaciones posteriores a la incorporación de ideas principalmente francesasse convirtieron en el patrimonio cultural (González, 2002). Y, posteriormente, se asentó el modernismo alemán implementado, inclusive, hasta el día de hoy.

Lo antes mencionado, desembocó en lo que se llama actualmente la identidad chilena, que surgió como producto de una evolución continua e inicialmente drástica. 
De esa manera, la identidad de Chile es el resultado de intervenciones, concentración de poder e influencias que llegaron para quedarse. Lo que se considera como patrimonio, urbanización, desarrollo, entre otros, parecen ser nociones traídas desde las grandes potencias económicas extranjeras, más que construcciones propias. De hecho, las imágenes de poder y costumbres "tradicionales" suelen ser injustificadas para nuestra cultura, memoria e historia. Aunado a ello, los materiales, la educación y las ideas de cómo el país debe ser trabajado, modificado y construido, responden a influencias importadas.

En todo caso, en Chile existe una identidad mestiza, que reniega de los pueblos originarios del territorio a causa de la búsqueda de ideales externos, a fin de llevar al país a un lugar o ranking más elevado y parecido al de las naciones definidas como "modelo" o ubicadas entre los "primeros 10 lugares de los ranking internacionales".

Lo anterior, es una consecuencia del eterno intervencionismo, principalmente norteamericano, que privilegia la cultura como objeto de mercado, así como la construcción rápida, pragmática y rentable, con una visión de progreso justificado para el desarrollo de los países; eso destruye la identidad e idiosincrasia cultural del patrimonio arquitectónico de las naciones como Chile (Costa, 2010).

Un reflejo de ese intervencionismo es evidente en la arquitectura, pues es muy común encontrarse con edificaciones geométricas (colmadas de ventanas), junto a edificios de la colonia española. Los patrones de vivienda y oficinas en la ciudad resultan claramente una respuesta económica a la problemática del constante aumento de la población. Incluso, ese crecimiento tiende a ser vertical, lo cual deriva en la construcción de grandes edificios, sin gran expresión cultural, ligadas al posmodernismo. Esas edificaciones resultan ajenas a la cotidianeidad de la población, por lo que habitualmente no funcionan y, finalmente, son transformados por cada habitante.

Un ejemplo claro de lo anterior, es lo que se denomina como intervención patrimonial. Al respecto, en todo el continente americano, desde el primer momento, los colonos se dedicaron a destruir lo que existía.

El Chile precolombino no posee mucha riqueza en cuanto a historia arquitectónica, pues la conquista española avasalladora y las costumbres que se fueron adquiriendo en esa época, transformaron rápidamente las chozas o rucas indígenas en casas construidas con adobe y tejas. Eso, hoy en día, también se 
expresa en los proyectos inmobiliarios asociados al turismo y a la recreación, pues se destruye el patrimonio en sitios arqueológicos de zonas mapuches, vinculadas a humedales y reservas, las cuales que constituían grandes espacios arquitectónicos naturales relacionados con la intervención espiritual de los antepasados de esas comunidades (Observatorio Latinoamericano de Conflictos Ambientales, 2018).

En todo caso:

'Esta modernidad se 'liquida' en el transcurso de una 'modernización' obsesiva y compulsiva que se propulsa e intensifica a sí misma, como resultado de la cual, a la manera del líquido (de ahí la elección del término) ninguna de las etapas consecutivas de la vida social puede mantener su forma durante un tiempo prolongado" (Bauman, 2013, p. 7, en Lourdes, 2014)

Bauman (citado en Lourdes, 2014) plantea, de manera certera, como la modernización transforma la vida social, por lo que nada logra ser permanente. Todo se pierde en el devenir de lo desechable y rápidamente renovable, con el fin de masificar el consumo y la burbuja del mercado inmobiliario.

\section{Talca y su identidad arquitectónica}

La zona del Maule, donde se encuentra emplazada Talca, fue estratégica durante la conquista y a mediados de 1800 , pues constituía un lugar con relaciones internacionales relevantes para el país.

La ciudad fue denominaba en un inicio como Villa San Agustín de Talca (en 1742) por el gobernador José Manso de Velasco. En ese entonces, se proyectaba "que la construcción de Talca sería de gran utilidad para el bien espiritual y material de las poblaciones del partido de Maule" (Memoria Chilena, s.f.).

Talca ha sido varias veces remodelada a través de los siglos, durante su proceso de construcción y expansión. Sin embargo, tras el terremoto del 27 de febrero de 2010, la ciudad perdió gran parte de su identidad arquitectónica, debido al sismo y a las erróneas políticas de reconstrucción.

Por lo anterior, los lugares característicos, las rutinas de vida y el patrimonio cultural de Talca jamás volverán a ser recuperados, ni en su edificación, ni en su esencia original, dado que se repite la historia de una transformación en pos de la modernidad, la cual busca evolución, rapidez y sincronía con el estándar 
pragmático, desvalorizando aquello que definimos como identidad, sentido de ciudad y territorio (Hurtado, 2014).

Al respecto, algunas de esas políticas impulsaron un boom inmobiliario en el valle central tras el 27 de febrero de 2010. Talca es la ciudad que más se ha urbanizado ante el crecimiento de la población (Ministerio del Desarrollo Social, 2011).

La ciudad se ha sobrepuesto a los predios agrícolas. Además, se alcanzaron los limites de los pueblos, creando conurbaciones en la mayor parte de los límites y un enorme contraste con el campo, el cual parece haber quedado en el pasado, aunque prevalecen las construcciones de adobe, debido a que este resulta unos de los materiales más accesible en las zonas rurales, en contraste con otros productos más procesados (acero, hormigón, aluminio, entre otros).

Otro hecho peculiar en la modernización de Talca, lo constituye la forma en la que se han manejado los proyectos que concursan en la rehabilitación de sectores históricos. Tal es el caso del Mercado Central de Talca, que fue declarado Monumento Nacional en el año 1998, gracias a la organización y requerimiento del sindicato de locatarios (Peldoza, 2010).

No obstante, con una larga historia de destrucción y remodelaciones, tras el 27 de febrero es innegable que peligra la esencia casi desvanecida del Mercado Central de Talca, pues este hoy se conserva únicamente en el sector norte (antiguos estacionamientos del Mercado). Allí, entre estructuras livianas provisorias, los locatarios trabajan y buscan, además de su sustento, mantener una tradición ya centenaria, y muchas veces familiar (Sivira, 2017).

Por otro lado, si bien el Consejo Municipal aprobó en el año 2019 los recursos para poder reconstruir el Mercado de Talca, se está exigiendo a los locatarios salir del lugar a fin de poder iniciar las obras, pero ese aspecto genera desconfianza en las personas, porque anteriormente se han revocado las patentes comerciales por la carencia de una edificación adecuada. Por ende, los locatarios exigen que la reconstrucción se realice por partes, sin tener que abandonar el espacio físico, tal como fue el caso del Hospital Regional de Talca (Hechavarría, 2019).

En otro orden de ideas, antes del terremoto del 27 de febrero de 2010, el sentido arquitectónico, cultural y de la comunidad que definía la estructura del Mercado era: a) núcleo central, allí se emplazaban las cocinerías y locales 
populares; b) pasillo circundante, se desarrollaba una feria libre; y, c) fachada, donde funcionaba el comercio estable.

No obstante, son diversos los proyectos y opiniones que han surgido sobre el futuro del lugar. Uno de los proyectos más bullados fue una propuesta de CorpGroup en 2010, que pretendía generar un centro cívico, con: dos playas subterráneas de estacionamiento, un supermercado (en el segundo nivel) y dejar en el primer nivel el Mercado propiamente como tal (Letelier, 2012), Sin embargo, la constructora desistió de participar, debido a la gran controversia que se generó por el descontento del sindicato del Mercado Central de Talca y de los apoderados de las escuelas municipales "Las Concentradas", que estaban incluidas en el mega proyecto (Giacaman, 2013).

En ese sentido, el sindicato del Mercado Central de Talca redactó una carta abierta, en la que planteó el aprecio a su identidad y la intención de mantenerla, dada la variedad de rubros de los locales, la relación de cercanía entre los comerciantes, la vida de barrio y la relación con los clientes (Sindicato de Locatarios, 2012).

Por su parte, Greene (2014) propuso generar un polo cultural, al convertir el núcleo del Mercado Central de Talca en un museo chileno del terremoto, mediante una reparación del daño estructural, pero conservando los escombros y destinando el pasillo circundante para los comerciantes.

Mientras que, Peldoza (2010) manifesta su preocupación por la incertidumbre en la que se encuentra el Mercado Central de Talca, al develar las estrategias poco transparentes de las autoridades para la reconstrucción del monumento nacional.

\section{Conclusión}

La idea de convertir el Mercado Central de Talca en un centro económico parece lógica, al considerar la ubicación y la vitalidad comercial que en él existe, sin embargo, su valor histórico es incalculable, por lo que sería prudente defender este territorio urbano, que identifica el espacio democrático como un patrimonio arquitectónico nacional.

A modo de recomendación, se sugiere rescatar la infraestructura física, distribuir los espacios en su totalidad, además de habilitar el pasillo circundante 
para convertir la feria libre preexistente en una feria de barrio permanente, con la finalidad de eliminar el comercio ambulante, tal como lo buscan las últimas legislaciones en esa materia (Lucena, 2018).

Finalmente, considerar los territorios de los cuáles se compone el Mercado, así como la ciudadanía que transita y convive en este espacio resulta clave y prioritario, dado el valor que entrega ese patrimonio arquitectónico histórico a la ciudad, Más aún, debido al auge de las "inmobiliarias capitalinas", las cuales están estructurando una nueva ciudad, con una orientación del modelo norteamericano, que busca propiciar lo simple o lo rápido, aún por encima del sentido cultural de las propias comunidades.

\section{REFERENCIAS BIBLIOGRÁFICAS}

COSTA, L. B. (2010). "La construcción y destrucción de la arquitectura en Chile". Revista AUS. Arquitectura/Urbanismo/Sustentabilidad, 8: 1-2.

DORMAELS, M. (2012). "Identidad, comunidades y patrimonio local: una nueva legitimidad social". Alteridades, 22: 9-19.

GIACAMAN, D. (2013). Alcalde reveló que Saieh no participará en licitación para reconstruir el Mercado de Talca. Diario El Centro. Rescatado de: https://issuu. com/diarioelcentro/docs/diario_22-09-2013

GONZÁLEZ, F. J. (2002). La influencia francesa en la vida social de Chile de la segunda mitad del siglo XIX, pág. 8. Rescatado de: https://docplayer.es/8073359La-influencia-francesa-en-la-vida-social-de-chile-de-la-segunda-mitad-del-sigloxix-francisco-javier-gonzalez-errazuriz.html

GREENE, R. (2014). "Por un museo chileno del terremoto". Revista Bifurcaciones, 15. Rescatado de: http://www.bifurcaciones.cl/2014/01/por-un-museo-chileno-delterremoto/

HECHAVARRÍA, M. (2019). Reconstrucción del Mercado de Talca crea incertidumbre en comerciantes. Diario El Centro. Rescatado de: http://www. diarioelcentro.cl/noticias/cronica/reconstruccion-del-mercado-de-talca-creaincertidumbre-en-comerciantes 
HERNÁNDEZ, L. (2017). La fragilidad del patrimonio cultural ante la modernidad líquida del siglo XXI. Rescatado de: https://senderosdelocultural.blogspot. com/2014/01/la-fragilidad-del-patrimonio-cultural.html

HURTADO, J. (2014). Talca: La "exitosa" y cruel reconstrucción. Radio Universidad de Chile. Rescatado de: https://radio.uchile.cl/2014/03/12/la-exitosa-y-cruelreconstruccion-el-caso-de-talca/

LETELIER, F. (2012). "La reconstrucción como marketing urbano/intentos de privatización de bienes públicos y luchas ciudadanas en Talca". Revista Bifurcaciones. Rescatado de: http://www.bifurcaciones.cl/2012/12/letelierreconstruccion-marketing-urbano/

LUCENA, W. (2018) Entre inquietudes y acuerdos corre el último mes de ambulantes en el centro. Diario El Centro. Rescatado de: https://issuu.com/ diarioelcentro/docs/diario_05-01-2018/2

MEMORIA CHILENA (s.f.). Fundación de ciudades: siglo XVIII. San Agustín de Talca. Rescatado de: http://www.memoriachilena.gob.cl/602/w3-article-92848. html

MEMORIA CHILENA (s.f.). La población durante el período colonial. Biblioteca Nacional Digital de Chile. Rescatado de: http://www.memoriachilena.gob.cl/602/ w3-article-703.html

MINISTERIO DE DESARROLLO SOCIAL (2011). Informe de Política Social (IPOS): Población. Rescatado de: http://www.ministeriodesarrollosocial.gob.cl/ ipos/

OBSERVATORIO LATINOAMERICANO DE CONFLICTOS AMBIENTALES (2018). Atropellos al patrimonio: Proyectos inmobiliarios y hallazgos arqueológicos mapuche. Rescatado de: http://olca.cl/articulo/nota.php?id=107139

PELDOZA, H. (2010). Mercado Central de Talca: el futuro incierto de un monumento nacional. Rescatado de: http://www.plataformaurbana.cl/archive/2010/12/17/ mercado-central-de-talca-el-futuro-incierto-de-un-monumento-nacional/

REAL ACADEMIA ESPAÑOLA (2019). Diccionario de la lengua española. En: https://dle.rae.es/?id=KtmKMfe 
SINDICATO DE LOCATARIOS (2012). Carta abierta del Sindicato de Locatarios del Mercado Central de Talca. Rescatado de: https://surmaule.wordpress. com/2012/06/30/carta-abierta-del-sindicato-de-locatarios-del-mercado-central-detalcal

SIVIRA, R. (2017). Diario El Centro: Reconstrucción del Mercado Central de Talca sigue esperando novedades. Rescatado de: https://issuu.com/diarioelcentro/docs/ diario_14f3b753c6f2f7

URIBE, N. (2014). "Patrimonialización comunitaria en barrios de Santiago: los casos de las zonas típicas de Viel y Yungay". Apuntes; 27: 80-93.

VULETICH M. Y NAVARRETE L. (2010). Biblioteca Nacional Digital de Chile. Memoria Chilena: Las corrientes socioculturales europeas durante el siglo XIX y sus influencias sobre nuestra identidad cultural. pág. 2. Rescatado de: http://www. memoriachilena.gob.cl/602/articles-123137_recurso_2.pdf 